\title{
Genetic architecture of variation in heading date among Asian rice accessions
}

\author{
Kiyosumi Hori ${ }^{1 \dagger}$, Yasunori Nonoue ${ }^{1,2 \dagger}$, Nozomi Ono², Taeko Shibaya' ${ }^{1}$ Kaworu Ebana', Kazuki Matsubara', \\ Eri Ogiso-Tanaka', Takanari Tanabata', Kazuhiko Sugimoto', Fumio Taguchi-Shiobara', Jun-ichi Yonemaru', \\ Ritsuko Mizobuchi', Yusaku Uga', Atsunori Fukuda', Tadamasa Ueda', Shin-ichi Yamamoto', Utako Yamanouchi', \\ Toshiyuki Takai', Takashi Ikka', Katsuhiko Kondo', Tomoki Hoshino', Eiji Yamamoto', Shunsuke Adachi', \\ Hideki Nagasaki ${ }^{1}$, Ayahiko Shomura ${ }^{1,2}$, Takehiko Shimizu ${ }^{1,2}$, Izumi Kono², Sachie Ito², Tatsumi Mizubayashi,2, \\ Noriyuki Kitazawa', Kazufumi Nagata', Tsuyu Ando ${ }^{1,2}$, Shuichi Fukuoka', Toshio Yamamoto ${ }^{1}$ and Masahiro Yano ${ }^{1 *}$
}

\begin{abstract}
Background: Heading date, a crucial factor determining regional and seasonal adaptation in rice (Oryza sativa L.), has been a major selection target in breeding programs. Although considerable progress has been made in our understanding of the molecular regulation of heading date in rice during last two decades, the previously isolated genes and identified quantitative trait loci (QTLS) cannot fully explain the natural variation for heading date in diverse rice accessions.

Results: To genetically dissect naturally occurring variation in rice heading date, we collected QTLs in advanced-backcross populations derived from multiple crosses of the japonica rice accession Koshihikari (as a common parental line) with 11 diverse rice accessions (5 indica, 3 aus, and 3 japonica) that originate from various regions of Asia. QTL analyses of over 14,000 backcrossed individuals revealed 255 QTLs distributed widely across the rice genome. Among the detected QTLs, 128 QTLs corresponded to genomic positions of heading date genes identified by previous studies, such as Hd1, Hd6, Hd3a, Ghd7, DTH8, and RFT1. The other 127 QTLs were detected in different chromosomal regions than heading date genes.
\end{abstract}

Conclusions: Our results indicate that advanced-backcross progeny allowed us to detect and confirm QTLs with relatively small additive effects, and the natural variation in rice heading date could result from combinations of large- and small-effect QTLs. We also found differences in the genetic architecture of heading date (flowering time) among maize, Arabidopsis, and rice.

Keywords: Oryza sativa L, Heading date, QTL, Natural variation, Genetic architecture

\section{Background}

Many plant species are able to flower in the seasons best suited to their reproduction. This ability depends mainly on the accurate measurement of seasonal changes in day length and temperature [1,2]. Rice is a short-day plant, i.e. it requires a photoperiod shorter than a critical day length for heading and flowering to occur [3].

\footnotetext{
* Correspondence: myano@affrc.go.jp

${ }^{\dagger}$ Equal contributors

'National Institute of Agrobiological Sciences, 2-1-2 Kannondai, 305-8602

Tsukuba, Ibaraki, Japan

Full list of author information is available at the end of the article
}

During last two decades, considerable progress has been made in our understanding of the molecular regulation of heading date in rice [4-9]. Rice photoperiodic flowering is controlled by two independent signaling pathways. The OsGI-Hd1-Hd3a pathway (rice GIGANTEA, Heading date 1, and Heading date $3 a$ ) is evolutionarily conserved in rice, as is the GI-CO-FT pathway (GIGANTEA, CONSTANS, and FLOWERING LOCUS T) in Arabidopsis. $H d 1$ was the first heading date QTL cloned on the basis of natural variation in rice accessions [10]. $H d 1$, a homolog of Arabidopsis CO, promotes heading under short-day length $(\mathrm{SD})$ conditions and represses it under long-day length (LD) conditions. $H d 1$

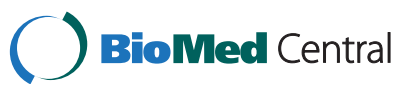

(c) 2015 Hori et al.; licensee BioMed Central. This is an Open Access article distributed under the terms of the Creative Commons Attribution License (http://creativecommons.org/licenses/by/4.0), which permits unrestricted use, distribution, and reproduction in any medium, provided the original work is properly credited. The Creative Commons Public Domain Dedication waiver (http://creativecommons.org/publicdomain/zero/1.0/) applies to the data made available in this article unless otherwise stated. 
promotes $H d 3 a$ expression under SD conditions, but inhibits $H d 3 a$ expression under LD conditions [11]. The repression of heading by $\mathrm{Hd} 1$ under $\mathrm{LD}$ conditions is enhanced by the kinase activity of Hd6 (Heading date 6), which is the $\alpha$-subunit of casein kinase $2[12,13]$. Hd3a functions as a florigen [14]. Another florigen gene, RFT1 (Rice flowering locus $T$ 1), is a tandemly duplicated para$\log$ of $\mathrm{Hd} 3 \mathrm{a}$ [15]. RFT1 expression increases under LD conditions, indicating that RFT1 is an LD-specific florigen $[16,17]$. The other signaling pathway includes Ehd1 (Early heading date 1) and Ghd7 (Grain number, plant height and heading date 7). Ehd1 encodes a B-type response regulator, which promotes flowering. Ehd1 affects the levels of $H d 3 a$ and RFT1 transcripts [18]. Ghd7 encodes a CCT (CO, CO-LIKE, and TIMING OF CAB1)domain protein. Ghd7 represses Ehd1, Hd3a, and RFT1 under LD conditions, but does not affect $H d 1$ mRNA levels [19]. Many other genes for heading date have been identified, and their genetic pathways have been well characterized in rice $[2,20]$.

A wide range of variation in heading date has been observed among rice accessions [3,8,21]. More than 650 QTLs for heading date have been detected using segregating populations derived from crosses among rice accessions and wild relatives; they are distributed over all 12 rice chromosomes (Q-TARO database; http://qtaro.abr.affrc.go.jp/ [22]; Gramene QTL database; http://archive.gramene.org/qtl/ [23]). To date, 13 QTLs have been cloned by map-based cloning strategies (OGRO database; http:// qtaro.abr.affrc.go.jp/ogro [24]): $H d 1$ [10], $H d 6$ [12], Hd3a [11], Ehd1 [18], Ghd7 [19], DTH8 (Days to heading on chromosome 8 [25]), DTH3 (Days to heading on chromosome 3 [26]), Hd17 (Heading date 17 [27]), DTH2 (Days to heading on chromosome 2 [28]), Hd16 (Heading date 16 [29,30]), RFT1 [15-17], Ehd4 (Early heading date 4 [31]), and OsPRR37 (Oryza sativa pseudo-response regulator 37 [32]). Sequence analysis of these genes indicated that allelic differences contribute greatly to heading date variation $[9,21]$. For example, functional and nonfunctional alleles of $H d 1$ are associated with late and early flowering, respectively, and $H d 1$ is a major determinant of natural variation in heading date in cultivated rice [10,33]. Deficient or weak alleles of Ghd7, DTH8, DTH2, Hd16, and OsPRR37 are distributed in northern cultivation areas at high latitudes $[19,25,28-30,32,34]$, strongly suggesting that such deficient and weak alleles are involved in the expansion of rice cultivation areas. Favorable alleles were probably selected by breeders to enhance rice productivity and adaptability for each cultivation region.

Genome-wide studies have revealed the divergence of the genetic architecture of flowering time or heading date control in other plant species such as Arabidopsis and maize [35,36]. In Arabidopsis, flowering time variation is controlled by allelic differences of a small number of genes with large genetic effects [36], whereas in maize natural variation of heading date is controlled by the additive effect of many QTLs with small effects [35]. We previously reported a QTL mapping study using $12 \mathrm{~F}_{2}$ populations derived from crosses of the $j a-$ ponica rice accession Koshihikari (KSH), a common parental line, with diverse accessions originating from various regions of Asia [21]. The study detected one to four QTLs with large effect in each $\mathrm{F}_{2}$ population; however, it also indicated that these QTLs cannot fully explain the varietal differences in heading date in some cross combinations. Generally, it is difficult to detect QTLs with small effects in primary mapping populations, e.g., $F_{2}$ populations [37]. Therefore, it is very likely that additional QTLs are also involved in the phenotypic variation for heading date in these populations.

To reveal the genetic architecture of natural variation for heading date in rice by detecting the hidden QTLs, we developed advanced-backcross populations $(>14,000$ plants) derived from crosses with the same $F_{2}$ populations. Advanced-backcross populations are promising materials for detecting a lot of QTLs involved in variation of heading date in Asian rice accessions. Detection both of large- and small-effect QTLs enable us to estimate the genetic architecture of heading date of Asian rice accessions. We compared genomic positions between detected QTLs and rice heading date genes previously isolated using the map-based cloning strategy, and investigated sequence polymorphisms of the heading date genes in Asian rice accessions. We also discuss similarities and differences in the genetic architectures of heading date (flowering time) among plant species.

\section{Methods}

\section{Plant materials}

We selected 11 rice accessions that originate from various regions of Asia to develop diverse backcrossed populations derived from crosses of these accessions with the japonica accession KSH as a common parental and recurrent line (Table 1; Additional file 1: Figure S1). The accessions (5 indica, 3 aus, and 3 japonica) were selected on the basis of their geographical origin, cluster analysis of genome-wide RFLP data, and variation in days to heading (DTH) from a representative rice collection $[38,39]$. These accessions were used previously as donor parents to produce $F_{2}$ populations [21] and backcrossed inbred lines at $\mathrm{BC}_{1} \mathrm{~F}_{6}$ generation [40]. Crosses were performed with $\mathrm{F}_{1}$ derived from crosses between those accessions and $\mathrm{KSH}$, and then backcrosses were performed to produce $\mathrm{BC}_{1} \mathrm{~F}_{1}$, $\mathrm{BC}_{2} \mathrm{~F}_{1}, \mathrm{BC}_{3} \mathrm{~F}_{1}$, and $\mathrm{BC}_{4} \mathrm{~F}_{1}$ individual plants (Additional file 2: Figure S2). From 29 to 39 individual plants were backcrossed in each generation of all of the 11 cross combinations. $\mathrm{BC}_{4} \mathrm{~F}_{1}$ plants were self-pollinated to produce $\mathrm{BC}_{4} \mathrm{~F}_{2}$ progenies, and $\mathrm{BC}_{4} \mathrm{~F}_{2}$ plants were self-pollinated to 
Table 1 List of 12 diverse accessions in Asian rice and their heading dates

\begin{tabular}{|c|c|c|c|c|c|c|c|}
\hline \multirow[b]{2}{*}{ Accession } & \multirow[b]{2}{*}{$I^{a}$} & \multirow[b]{2}{*}{ Abbreviation } & \multirow[b]{2}{*}{ Subspecies } & \multirow[b]{2}{*}{ Cultivar group $^{b}$} & \multirow[b]{2}{*}{ Origin } & \multicolumn{2}{|l|}{$\mathrm{DTH}^{\mathrm{c}}$} \\
\hline & & & & & & ND & SD \\
\hline Koshihikari & & $\mathrm{KSH}$ & japonica & A & Japan & $106.6 \pm 0.6$ & $49.5 \pm 0.5$ \\
\hline Hayamasari & & HAY & japonica & A & Japan & $71.8 \pm 1.5$ & $54.5 \pm 0.7$ \\
\hline Qiu Zhao Zong & WRC10 & QZZ & indica & C & China & $88.2 \pm 0.8$ & $62.5 \pm 1.0$ \\
\hline Tupa 121-3 & WRC32 & TUP & aus & B & Bangladesh & $102.4 \pm 1.5$ & $68.0 \pm 1.1$ \\
\hline Muha & WRC25 & MUH & aus & B & India & $105.6 \pm 1.1$ & $71.2 \pm 2.9$ \\
\hline Basilanon & WRC44 & BAS & aus & B & Philippines & $115.0 \pm 3.0$ & $116.3 \pm 2.5$ \\
\hline Deng Pao Zhai & WRC19 & $\mathrm{DPZ}$ & indica & C & China & $119.2 \pm 0.5$ & $61.9 \pm 3.8$ \\
\hline Khau Mac Kho & WRC48 & KMK & japonica & A & Vietnam & $126.2 \pm 0.4$ & $86.7 \pm 1.8$ \\
\hline Naba & WRC05 & NAB & indica & C & India & $128.0 \pm 1.2$ & $66.7 \pm 0.8$ \\
\hline Bei Khe & WRC03 & $\mathrm{BKH}$ & indica & C & Cambodia & $130.0 \pm 1.7$ & $61.9 \pm 3.0$ \\
\hline Khao Nam Jen & WRC68 & KNJ & japonica & A & Laos & $186.3 \pm 2.9$ & $59.8 \pm 1.4$ \\
\hline Bleiyo & WRC63 & BLE & indica & C & Thailand & $190.8 \pm 1.0$ & $40.4 \pm 0.5$ \\
\hline
\end{tabular}

${ }^{\mathrm{a}}$ Accession IDs were selected from the world rice collection (WRC) [38].

${ }^{b}$ Cultivar groups are based on the classification of [38]. Groups A, B, and C correspond to japonica, aus, and indica, respectively.

'Days to heading (DTH) were scored under different day-length conditions. ND, the experimental field of National Institute ofAgrobiological Sciences, Tsukuba,

Ibaraki, Japan $\left(36^{\circ} \mathrm{N}\right)$; SD, short-day length condition (10 h light/14 h dark); LD,long-day length condition (14.5 h light/9.5 h dark). DTH is shown as

mean \pm standard deviation.

produce $\mathrm{BC}_{4} \mathrm{~F}_{3}$ progenies. We used $\mathrm{BC}_{4} \mathrm{~F}_{2}$ populations for QTL detection, and $\mathrm{BC}_{4} \mathrm{~F}_{3}$ populations for confirmation of additive effects and chromosomal regions of the putative QTLs.

\section{Scoring of DTH}

In each $\mathrm{BC}_{4} \mathrm{~F}_{2}$ population, 24 plants were grown in 2010 and 2011 in a paddy field at the National Institute of Agrobiological Sciences (NIAS) in Tsukuba, Japan $\left(36^{\circ} 03^{\prime} \mathrm{N}\right.$, $\left.140^{\circ} 11^{\prime} \mathrm{E}\right)$. In each $\mathrm{BC}_{4} \mathrm{~F}_{3}$ population, 96 and 192 plants were grown in 2012 and 2013 in the same paddy field at the NIAS. Seeds were sown in April, and seedlings were transplanted to the paddy field in May (two rows per $\mathrm{BC}_{4} \mathrm{~F}_{2}$ and $\mathrm{BC}_{4} \mathrm{~F}_{3}$ population with a distance of $18 \mathrm{~cm}$ between plants and $30 \mathrm{~cm}$ between rows). The mean day-lengths during the cultivation periods were $13.1 \mathrm{~h}$ in April, $14.1 \mathrm{~h}$ in May, $14.6 \mathrm{~h}$ in June, $14.4 \mathrm{~h}$ in July, $13.5 \mathrm{~h}$ in August, and 12.4 h in September. Average temperatures during the cultivation periods were $17^{\circ} \mathrm{C}$ in May, $21^{\circ} \mathrm{C}$ in June, $24^{\circ} \mathrm{C}$ in July, $26^{\circ} \mathrm{C}$ in August, and $22^{\circ} \mathrm{C}$ in September. Cultivation management followed the standard procedures used at NIAS. DTH in the individual backcrossed plants were scored as the number of days from sowing to the appearance of the first panicle. For the parental accessions, DTH were scored in 24 plants per line and mean values were calculated for each line.

The 12 parental accessions were grown in a controlledenvironment cabinet under SD conditions (10 h light/14 h dark, at $28^{\circ} \mathrm{C}$ for $12 \mathrm{~h} / 24^{\circ} \mathrm{C}$ for $12 \mathrm{~h}$ ) and $\mathrm{LD}$ conditions (14.5 h light $/ 9.5 \mathrm{~h}$ dark, at $28^{\circ} \mathrm{C}$ for $12 \mathrm{~h} / 24^{\circ} \mathrm{C}$ for $12 \mathrm{~h}$ ). The relative humidity was maintained at $60 \%$ under a photosynthetic photon flux density of $500 \mu \mathrm{mol} \mathrm{m} \mathrm{m}^{-2} \mathrm{~s}^{-1}$ provided by metal halide lamps that covered the spectrum from 300 to $1000 \mathrm{~nm}$. DTH in 10 plants of each accession were scored and mean values were calculated for each accession.

\section{DNA marker analysis}

Total genomic DNA of individual backcrossed plants and parental accessions was extracted from $1-3 \mathrm{~cm}$ fresh leaves crushed in $250 \mu \mathrm{L}$ extraction buffer containing $1 \mathrm{M}$ $\mathrm{KCl}, 100 \mathrm{mM}$ Tris- $\mathrm{HCl}(\mathrm{pH} 8.0)$, and $10 \mathrm{mM}$ EDTA. DNA was precipitated with $100 \mu \mathrm{L}$ 2-propanol, washed with $150 \mu \mathrm{L} 70 \%$ ethanol, and dissolved in $30 \mu \mathrm{L}$ buffer containing $1 \mathrm{mM}$ Tris- $\mathrm{HCl} \mathrm{pH} 8.0$ and $0.1 \mathrm{mM}$ EDTA, $\mathrm{pH}$ 8.0. Simple sequence repeats (SSRs) were used as DNA markers for linkage map construction and QTL detection. SSR markers were selected from those described by previous studies $[41,42]$. Polymorphism detection procedures for the SSR markers have been described by [21]. Gene-specific markers were used to determine precise genomic positions of 13 heading date genes, $H d 1, H d 6$, Hd3a, Ehd1, Ghd7, DTH8, DTH3, DTH2, Hd17, Hd16, RFT1, OsPRR37, and Ehd4 [15,21,26-29,31,34,40,43].

\section{QTL analysis in advanced-backcross populations}

For linkage mapping, version 3.0 of MAPMAKER/EXP [44] was used. The Kosambi mapping function was used to calculate genetic distances [45]. QTL analysis was performed using composite interval mapping as implemented by the Zmapqtl program provided by version 2.5 of the QTL Cartographer software [46]. Genome-wide threshold values $(\alpha=0.05)$ were used to detect QTLs based on the results of 1,000 permutations. LOD thresholds 
from 2.0 to 2.8 were used in the QTL analyses of the $\mathrm{BC}_{4} \mathrm{~F}_{3}$ populations.

\section{Sequencing of a heading date gene $D T H 8$}

All exons of the DTH8 gene were amplified with specific primers [34] by PCR on genomic DNA of the 12 rice accessions. Amplified DNA fragments were purified and sequenced with the Sanger dideoxy terminator method [47]. To ensure that the sequence data were of high quality (phred score $>30$ ), re-sequencing was performed when necessary. Each sequence read was individually mapped onto the Nipponbare reference coding region sequence to ensure that all exons of DTH8 were covered.

\section{Results}

\section{Variation in heading date of Asian rice accessions}

DTH of the 12 rice accessions varied from 71.8 (extremely early) to 190.8 (extremely late) under natural-day length (ND) conditions (Table 1). Four rice accessions, Hayamasari (HAY), Qiu Zhao Zong (QZZ), Tupa 121-3 (TUP), and Muha (MUH) had earlier heading than KSH. Seven accessions, Basilanon (BAS), Deng Pao Zhai (DPZ), Khao Mac Kho (KMK), Naba (NAB), Bei Khe (BKH), Khao Nam Jen (KNJ), and Bleiyo (BLE), had later heading than $\mathrm{KSH}$. BLE and KNJ showed extremely late heading in comparison with KSH ( $>80$ days). Under SD conditions, $\mathrm{BLE}, \mathrm{KSH}$, and HAY had relatively early heading, whereas KMK and BAS had late heading (Table 1; Additional file 1: Figure S1). Under LD conditions, HAY and QZZ had relatively early heading, whereas BAS, KNJ, and BLE had late heading. In BLE, DTH was $>280$ under LD conditions (Table 1; Additional file 1: Figure S1). DTH of HAY, QZZ, and BAS was similar under ND, SD, and LD conditions, indicating that these accessions are photoperiod-insensitive. DTH of NAB, KNJ, and BLE was much lower under SD conditions than under LD conditions, indicating that these accessions are strongly photoperiod-sensitive.

\section{Variation in heading date in the $\mathrm{BC}_{4} \mathrm{~F}_{2}$ populations}

We developed $\mathrm{BC}_{4} \mathrm{~F}_{2}$ populations in which particular heterozygous chromosome region(s) of donor accessions segregated in the $\mathrm{KSH}$ genetic background (Additional file 2: Figure S2; Additional file 3: Figure S3). In each cross combination between $\mathrm{KSH}$ and the 11 donor accessions, 39 $\mathrm{BC}_{4} \mathrm{~F}_{2}$ populations were developed $\left(366 \mathrm{BC}_{4} \mathrm{~F}_{2}\right.$ populations, $>8,700$ backcrossed individual plants in total). These $\mathrm{BC}_{4} \mathrm{~F}_{2}$ populations covered the whole genomes of the 11 donor accessions. Most plants in the $\mathrm{BC}_{4} \mathrm{~F}_{2}$ populations and the recurrent parent $\mathrm{KSH}$ showed similar numbers of DTH (statistically non-significant at the $5 \%$ level by the Dunnett's multiple comparison test). However, several plants showed earlier or later heading than $\mathrm{KSH}$, indicating that heading date QTLs were segregating in the heterozygous chromosomal regions in these $\mathrm{BC}_{4} \mathrm{~F}_{2}$ populations. $\mathrm{BC}_{4} \mathrm{~F}_{2}$ plants with heading date earlier than that of $\mathrm{KSH}$ were observed in all cross combinations except $\mathrm{KNJ} / \mathrm{KSH}$ and BLE/KSH populations (Figure 1; Additional file 4: Table $\mathrm{S} 1) . \mathrm{BC}_{4} \mathrm{~F}_{2}$ plants with later heading than that of $\mathrm{KSH}$ were observed in all 11 cross combinations. No $\mathrm{BC}_{4} \mathrm{~F}_{2}$ plants had similar heading date with $\mathrm{HAY}$, QZZ, $\mathrm{KNJ}$, or BLE, i.e. the extremely early- or late-heading donor accessions.

\section{QTL detection in the $\mathrm{BC}_{4} \mathrm{~F}_{2}$ populations}

In the $366 \mathrm{BC}_{4} \mathrm{~F}_{2}$ populations, a total of 255 QTLs were detected with the LOD scores of $>2.0$ (Figure 2; Additional file 5: Table S2). Among them, 173 had a LOD score of $>3.0$ and 134 had a score of $>4.0$. Previously, 13 heading date QTLs have been isolated and assigned to specific photoperiod flowering pathways in rice $[8,9]$. Among the 255 newly detected QTLs, 128 corresponded well to genomic positions of the 13 heading date genes (Figure 2; Additional file 5: Table S2). At the position of Hd1 gene (chromosome 6), 34 QTLs were detected. At the position of Ghd7 gene (chromosome 7), 10 QTLs were detected. At the position of DTH8 gene (short arm of chromosome 8), 12 QTLs were detected. Near $H d 17$, RFT1, and Hd3a genes (short arm of chromosome 6), 13 QTLs were detected. Near Hd6 and Hd16 genes (long arm of chromosome 3), 24 QTLs were detected. Near DTH2 gene (long arm of chromosome 2), 6 QTLs were detected. Near Ehd4 and DTH3 genes (short arm of chromosome 3), 14 QTLs were detected. Near OsPRR37 gene (long arm of chromosome 7), 10 QTLs were detected. And, near Ehd1 gene (chromosome 10), 3 QTLs were detected. Almost all of these QTLs corresponded well to those detected in $F_{2}$ populations derived from the same cross combinations in the previous study [21].

The remaining 127 of the 255 QTLs were found in genomic regions different from those of the 13 isolated genes (Figure 2; Additional file 5: Table S2). LOD scores $>3.0$ were detected for 55 QTLs and LOD scores $>4.0$ were detected for 29 QTLs. These QTLs were distributed over all 12 chromosomes. QTL clusters were found in several chromosomal regions, such as the proximal region of the short arm on chromosome 3, distal end of the long arm on chromosome 5, and centromeric region of chromosome 8 (Figure 2). Our results indicate that, in addition to the alleles of the previously isolated genes, a number of QTLs contribute to phenotypic variation in heading date of Asian rice accessions.

Among the 255 QTLs, the values of significant additive effects of the KSH alleles ranged from -15.1 to 10.9 days (Figure 3; Additional file 5: Table S2) in comparison with the donor parent alleles. In 174 QTLs (68.2\%), the KSH alleles showed earliness additive effects, whereas in 81 QTLs (31.8\%), the KSH alleles showed lateness additive 


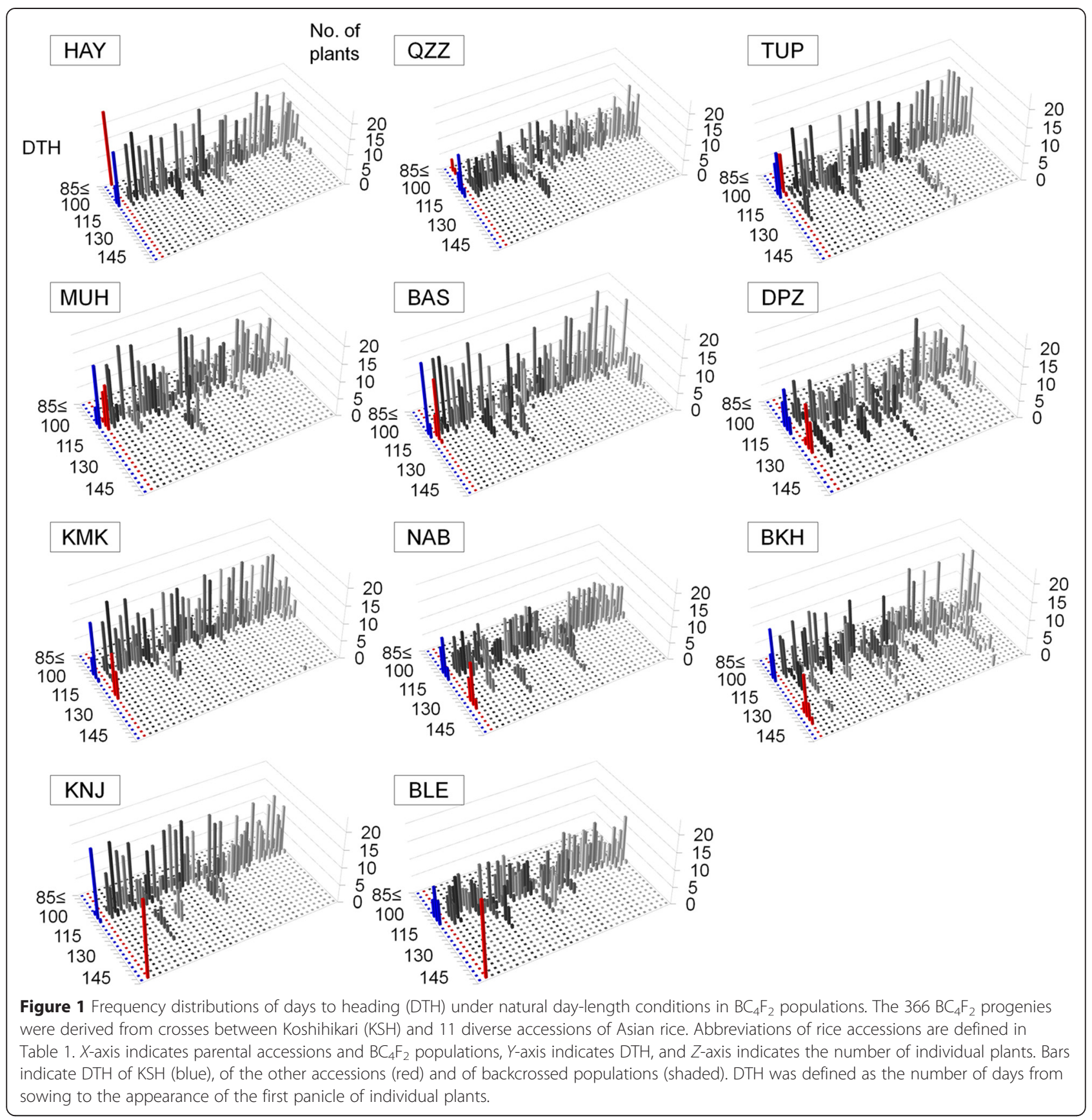

effects. In 130 QTLs (51.0\%), additive effects of KSH alleles of $<3$ days were observed, whereas in 125 QTLs (49.0\%) these effects were $>3$ days. We detected similar numbers of QTLs showing small or large additive effects in this study. The 128 QTLs located near the 13 genes isolated previously had relatively large additive effects, whereas the other 127 QTLs had relatively small additive effects (Additional file 5: Table S2).

The cummulative additive effects of QTLs detected in 12 accessions and their DTH under ND conditions showed a significant correlation $\left(R^{2}=0.78\right.$, Figure 4$)$.
Total additive effects of all QTLs reliably predicted the order of heading dates of the 12 donor accessions. HAY and QZZ were predicted to have early heading dates, whereas KNJ and BLE were predicted to have late heading. The predicted heading dates had the same order as the actual heading dates under ND condition in the 12 rice accessions. However, the predicted heading dates deviated from actual heading dates under ND conditions in extremely-early and extremely-late heading accessions. Actual heading dates of HAY and QZZ were 34.8 and 18.4 days earlier, respectively, than that of $\mathrm{KSH}$ 


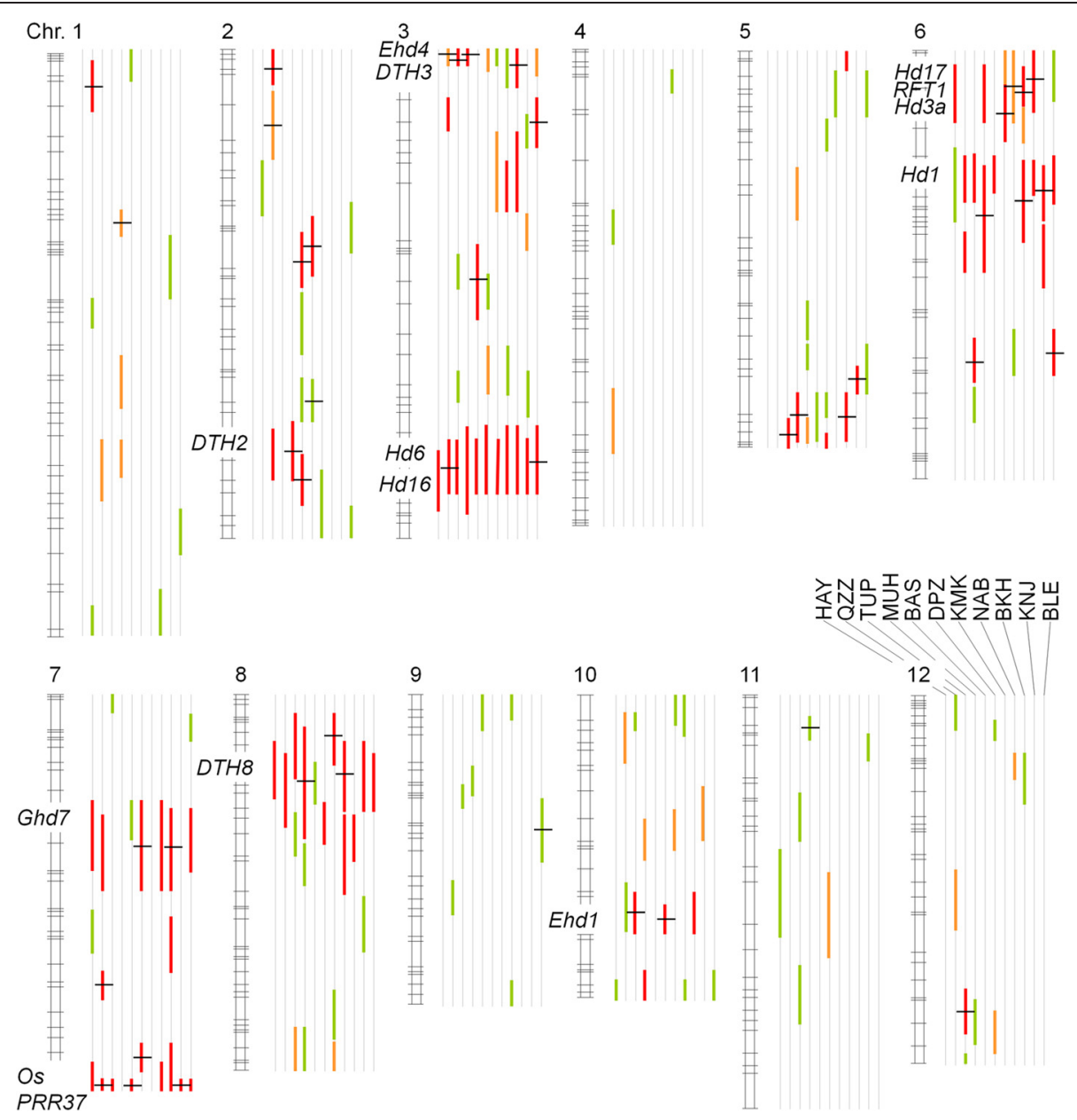

Figure 2 Chromosomal locations of QTLs for days to heading (DTH) under natural day-length conditions detected in $\mathrm{BC}_{4} \mathrm{~F}_{2}$ populations. QTLS were detected in $366 \mathrm{BC}_{4} \mathrm{~F}_{2}$ populations derived from crosses between Koshihikari (KSH) and 11 diverse accessions of Asian rice. Consensus linkage maps of 12 rice chromosomes are depicted as ladder-structured boxes; approximate locations of 13 heading date genes isolated previously are shown. QTL positions are oriented from Hayamasari (HAY) (left) to Bleiyo (BLE) (right) in the same order as in Table 1. Vertical bars indicate confidence intervals of QTLs (2-LOD reduction on each side of the peak) and show peak LOD scores of 2.0-3.0 (green), 3.0-4.0 (orange), and >4.0 (red). Horizontal thick bars on the QTL intervals indicate those confirmed in $53 \mathrm{BC}_{4} \mathrm{~F}_{3}$ populations.

under ND conditions (Table 1), whereas predicted heading dates of HAY and QZZ were only 9.1 and 7.6 days earlier. Actual heading dates of KNJ and BLE were 79.4 and 83.4 days later, respectively, than that of $\mathrm{KSH}$ under ND conditions (Table 1), whereas predicted heading dates were 31.2 and 52.5 days later.

\section{Confirmation of QTLs in the $\mathrm{BC}_{4} \mathrm{~F}_{3}$ populations}

In small-sized populations, it may be difficult to detect reliable QTLs because of the possibility of false positive detection [37]. To confirm the genetic effects of the QTLs detected in the $\mathrm{BC}_{4} \mathrm{~F}_{2}$ populations, we selected 56 QTLs that included both large- and small-effect QTLs distributed across the rice genome. We developed and analyzed $53 \mathrm{BC}_{4} \mathrm{~F}_{3}$ populations consisting of $>6,000$ backcrossed individual plants (96 or 192 plants in each population). In these $\mathrm{BC}_{4} \mathrm{~F}_{3}$ populations, we confirmed the presence of all 56 QTLs detected in the $\mathrm{BC}_{4} \mathrm{~F}_{2}$ populations (Table 2; Additional file 5: Table S2).

Among small-effect QTLs, we focused on seven QTLs chosen on the basis of the size of additive effect and genomic position (Figure 5): these QTLs had additive effects of $<3$ days and their locations were different from those of heading date genes isolated previously. In QZZ/KSH, the additive effects of the KSH alleles of the QTL on the short arm of chromosome 1 were 2.2 days in the $\mathrm{BC}_{4} \mathrm{~F}_{2}$ population and 1.7 days in the $\mathrm{BC}_{4} \mathrm{~F}_{3}$ population. In TUP/KSH, the additive effects of the KSH alleles of the two QTLs on the short arm of chromosome 2 were 2.1 and -1.6 days in the $\mathrm{BC}_{4} \mathrm{~F}_{2}$ populations and 1.6 and -1.4 days in the $\mathrm{BC}_{4} \mathrm{~F}_{3}$ populations. In $\mathrm{DPZ} / \mathrm{KSH}$, the additive effects of the $\mathrm{KSH}$ alleles of the QTL on the long arm of chromosome 2 were -1.9 days in the $\mathrm{BC}_{4} \mathrm{~F}_{2}$ population and -1.1 days in the $\mathrm{BC}_{4} \mathrm{~F}_{3}$ population. In TUP/KSH, the additive effects of 


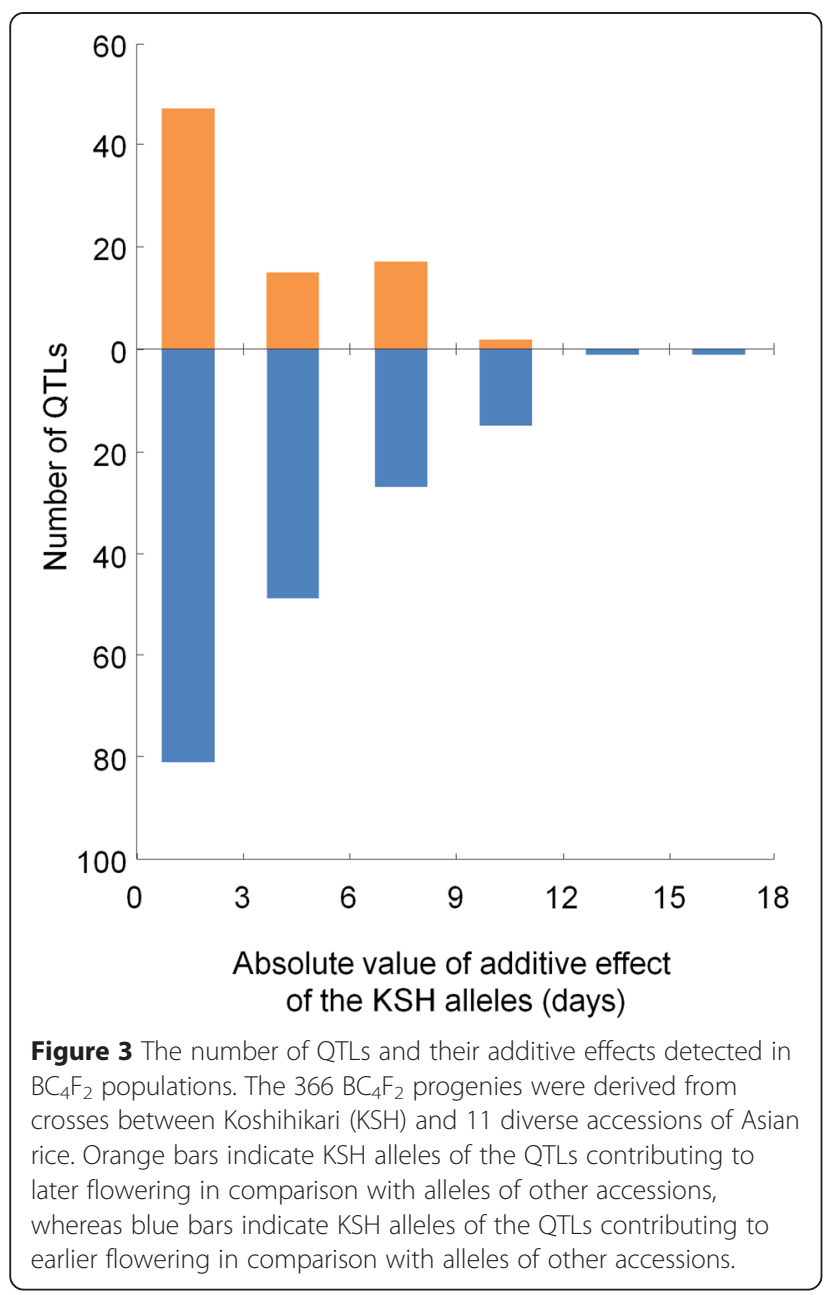

the KSH alleles of the QTL on the long arm of chromosome 5 were -1.1 days in the $\mathrm{BC}_{4} \mathrm{~F}_{2}$ population and -1.3 days in the $\mathrm{BC}_{4} \mathrm{~F}_{3}$ population. In $\mathrm{KNJ} / \mathrm{KSH}$, the additive effects of the $\mathrm{KSH}$ alleles of the other QTL on the long arm of chromosome 5 were -2.2 days in the $\mathrm{BC}_{4} \mathrm{~F}_{2}$ population and -1.8 days in the $\mathrm{BC}_{4} \mathrm{~F}_{3}$ population. In $\mathrm{KMK} / \mathrm{KSH}$, the additive effects of the $\mathrm{KSH}$ alleles of the two QTLs on the short arm of chromosome 8 were -2.5 days and -1.3 days in the two $\mathrm{BC}_{4} \mathrm{~F}_{2}$ populations, and -1.3 days in the $\mathrm{BC}_{4} \mathrm{~F}_{3}$ populations. Using the $\mathrm{BC}_{4} \mathrm{~F}_{3}$ populations, we even confirmed the existence of small-effect QTLs with additive effects of $<3$ days.

For the same seven QTLs, we tried to delimit their chromosomal regions by substitution mapping in the $\mathrm{BC}_{4} \mathrm{~F}_{3}$ populations, even though only a small number of $\mathrm{BC}_{4} \mathrm{~F}_{3}$ progenies had recombination within the QTL regions (Figure 6). In the QZZ/KSH population, the QTL on the short arm of chromosome 1 was located within $\sim 7.3 \mathrm{Mbp}$ of the marker interval from the distal end of the arm to RM3598. In the TUP/KSH population, the two QTLs on the short arm of chromosome 2 were located within $\sim 6.7 \mathrm{Mbp}$ of the interval from the distal

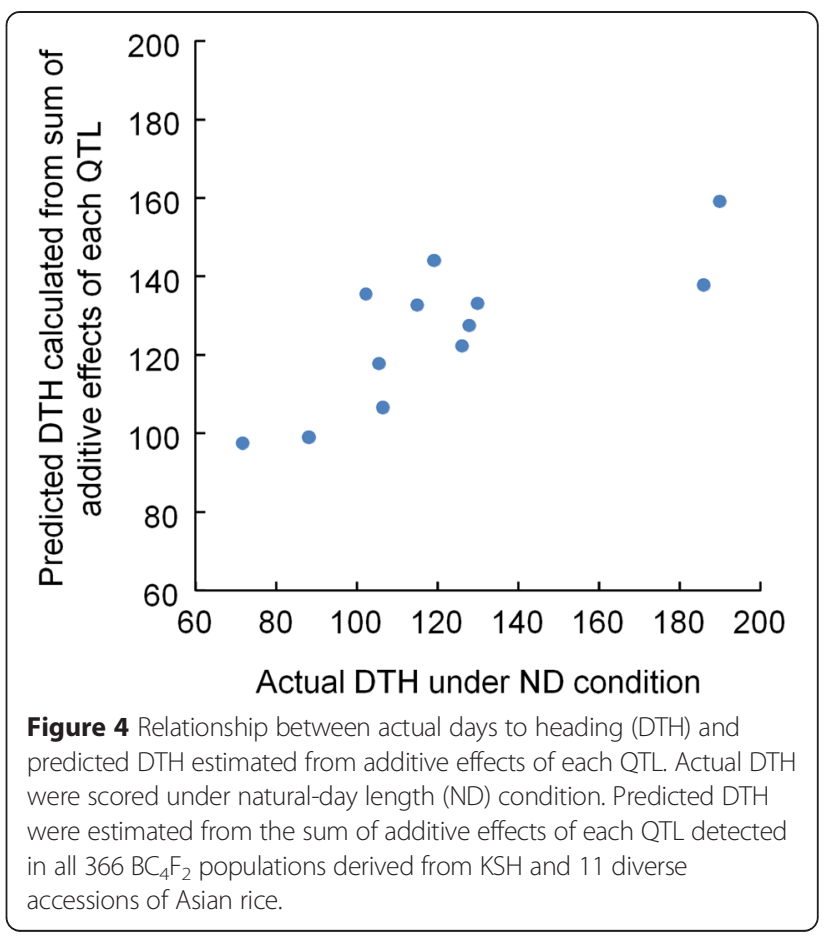

end of the arm to RM5897 and within $16.6 \mathrm{Mbp}$ of the RM7562-RM1211 interval. In the DPZ/KSH population, the QTL on the long arm of chromosome 2 was located within $\sim 6.1 \mathrm{Mbp}$ of the interval from the distal end of the arm to RM6933. On the long arm of chromosome 5, the two QTLs were narrowed down to within $~ 5.6 \mathrm{Mbp}$ of the interval from the distal end of the arm to RM3476 in the TUP/KSH population, and within $~ 4.0$ $\mathrm{Mbp}$ of the interval from the distal end of the arm to RM3476 in the $\mathrm{KNJ} / \mathrm{KSH}$ population. In the KMK/KSH population, the QTL on the short arm of chromosome 8 was located within $\sim 3.7 \mathrm{Mbp}$ of the interval from the distal end of the arm to RM1148. Our results clearly delimit significant marker intervals that include smalleffect QTLs using advanced-backcross progenies.

\section{Discussion}

Many genetic studies have focused on cloning genes or QTLs for heading date in rice, and a detailed genetic control pathway has been revealed [2,8,9]. In most cases, QTLs with large effects have been studied as targets for genetic analysis and molecular characterization. The role of QTLs with small-effects in heading date variation among rice accessions still remains unclear.

We demonstrated the potential utility of advancedbackcross populations in genetic analysis of natural variation in heading date, in particular, detection of small-effect QTLs. We found that 130 QTLs (51.0\%) had additive effects of $<3$ days. Most of these QTLs were found in different chromosomal regions than the 
Table 2 Heading date QTLs confirmed in $\mathrm{BC}_{\mathbf{4}} \mathrm{F}_{\mathbf{3}}$ populations

\begin{tabular}{|c|c|c|c|c|c|c|c|c|c|}
\hline Population & Chromosome & Physical position ofQTL (Mbp) & Marker interval & $\operatorname{LOD}^{a}$ & Additive effect $^{b}$ & Dominance effect $^{c}$ & PVE (\%) ${ }^{d}$ & Corresponding gene $\mathrm{e}^{\mathrm{e}}$ & Located near gene $^{f}$ \\
\hline \multirow[t]{5}{*}{ QZZ } & 1 & $0.2-10.8$ & RM6887-RM1287 & 5.3 & 1.7 & 0.2 & 20.0 & & \\
\hline & 3 & $0.5-5.5$ & RM4108-RM5442 & 12.1 & -1.7 & 0.2 & 52.1 & & Ehd4, DTH3 \\
\hline & 3 & $30.4-35.6$ & RM3199-RM3329 & 36.2 & -8.1 & 4.0 & 77.5 & Hd6 & Hd16 \\
\hline & 7 & $7.1-13.4$ & RM21251-RM7273 & 32.1 & 10.9 & 8.6 & 89.9 & Ghd7 & \\
\hline & 7 & $26.8-29.4$ & RM1364-RM22164 & 2.4 & 3.3 & -0.1 & 5.7 & & OsPRR37 \\
\hline \multirow[t]{9}{*}{ TUP } & 2 & 1.9 & RM7562 & 8.3 & 1.6 & 0.0 & 37.6 & & \\
\hline & 2 & $6.7-11.3$ & RM5897-RM1234 & 6.8 & -1.4 & -0.2 & 26.4 & & \\
\hline & 2 & $27.1-30.6$ & RM1367-RM3316 & 4.1 & -0.5 & -0.8 & 13.2 & & DTH2 \\
\hline & 3 & 0.5 & RM4108 & 19.0 & -2.4 & -0.6 & 54.6 & & Ehd4, DTH3 \\
\hline & 4 & $2.0-11.6$ & RM5414-RM16606 & 2.8 & 0.7 & -0.8 & 20.9 & & \\
\hline & 5 & $23.9-29.5$ & RM3476-RM3286 & 14.6 & -1.3 & 0.4 & 35.0 & & \\
\hline & 6 & $24.5-26.0$ & RM5957-RM6395 & 5.0 & -0.8 & -0.1 & 22.5 & & \\
\hline & 10 & $11.7-17.4$ & RM4455-RM5620 & 2.5 & -0.5 & -0.9 & 18.3 & & Ehd 1 \\
\hline & 12 & $20.0-24.4$ & RM28305-RM5479 & 8.5 & -0.9 & -0.4 & 19.7 & & \\
\hline \multirow[t]{6}{*}{ MUH } & 3 & $0.5-1.5$ & RM4108-RM3372 & 12.6 & -2.0 & 0.3 & 47.6 & & Ehd4, DTH3 \\
\hline & 5 & $23.9-27.9$ & RM3476-RM5784 & 9.5 & -1.9 & 0.4 & 16.1 & & \\
\hline & 6 & $8.1-8.8$ & RM19725-RM5963 & 26.1 & 4.2 & -1.1 & 67.3 & $\mathrm{Hd} 1$ & \\
\hline & 6 & $15.8-20.3$ & RM20023-RM7193 & 20.8 & 4.6 & -0.4 & 66.1 & & \\
\hline & 8 & $6.8-10.3$ & RM22617-RM3395 & 25.0 & -4.0 & 0.5 & 74.0 & DTH8 & \\
\hline & 11 & $3.8-8.1$ & RM5599-RM3701 & 2.2 & 0.5 & -0.9 & 3.9 & & \\
\hline \multirow[t]{6}{*}{ BAS } & 2 & $11.3-13.5$ & RM1234-RM13106 & 4.4 & -0.6 & 0.0 & 9.8 & & \\
\hline & 2 & $33.0-35.4$ & RM7286-RM3850 & 3.6 & -1.1 & 0.7 & 8.5 & & DTH2 \\
\hline & 3 & $6.9-10.1$ & RM3872-RM14778 & 7.0 & -1.1 & 0.2 & 17.4 & & Ehd4, DTH3 \\
\hline & 3 & $10.1-14.5$ & RM14778-RM6959 & 4.3 & -1.1 & 0.7 & 9.8 & & \\
\hline & 3 & $17.4-21.4$ & RM1334-RM5488 & 7.9 & -0.9 & -0.4 & 16.7 & & \\
\hline & 7 & 29.4 & RM22164 & 21.0 & -3.7 & -0.1 & 69.7 & & OsPRR37 \\
\hline \multirow[t]{6}{*}{ DPZ } & 2 & $13.4-18.4$ & RM13101-RM1211 & 2.5 & -1.0 & 0.0 & 5.4 & & \\
\hline & 2 & $29.3-35.4$ & RM6933-RM3850 & 9.2 & -1.1 & 0.3 & 38.3 & & DTH2 \\
\hline & 6 & 0.2 & RM6467 & 39.5 & -3.6 & -3.3 & 85.2 & & \\
\hline & 7 & $13.2-16.2$ & RM21433-RM5481 & 10.6 & -4.0 & -0.9 & 42.5 & Ghd7 & \\
\hline & 7 & $28.1-29.4$ & RM22105-RM22164 & 31.6 & -5.0 & 0.0 & 53.4 & & OsPRR37 \\
\hline & 10 & $17.5-20.7$ & RM5620-RM25771 & 5.3 & 0.5 & 0.1 & 18.2 & & Ehd 1 \\
\hline
\end{tabular}


Table 2 Heading date QTLs confirmed in $\mathrm{BC}_{4} \mathrm{~F}_{3}$ populations (Continued)

\begin{tabular}{|c|c|c|c|c|c|c|c|c|c|}
\hline & 12 & $7.1-10.1$ & RM27792-RM6973 & 5.7 & -0.6 & -0.1 & 20.1 & & \\
\hline \multirow[t]{4}{*}{ KMK } & 2 & $4.3-9.5$ & RM4355-RM12921 & 2.2 & 0.5 & -0.3 & 7.8 & & \\
\hline & 2 & $20.1-24.0$ & RM1379-RM3515 & 2.1 & 0.5 & 0.2 & 7.3 & & \\
\hline & 6 & 8.1 & RM19725 & 34.4 & 4.0 & -0.8 & 81.0 & $\mathrm{Hd} 1$ & \\
\hline & 8 & $3.0-3.7$ & RM4955-RM1148 & 9.5 & -1.3 & 0.2 & 45.4 & & \\
\hline \multirow[t]{7}{*}{ NAB } & 2 & $27.1-34.7$ & RM1367-RM3789 & 2.2 & -0.6 & 0.1 & 5.5 & & DTH2 \\
\hline & 3 & $9.9-15.0$ & RM1371-RM3204 & 13.4 & -1.6 & 0.2 & 43.6 & & Ehd4, DTH3 \\
\hline & 5 & 27.9-29.7 & RM5784-RM19218 & 7.0 & -1.0 & 0.2 & 18.7 & & \\
\hline & 6 & $0.2-2.2$ & RM6467-RM8112 & 10.7 & 1.3 & 0.1 & 29.1 & & $\mathrm{Hd} 17$ \\
\hline & 6 & $8.8-13.0$ & RM5963-RM19951 & 30.2 & 5.9 & 0.6 & 79.2 & $\mathrm{Hd} 1$ & \\
\hline & 8 & 5.9 & RM6838 & 5.5 & -1.8 & 0.3 & 7.9 & DTH8 & \\
\hline & 9 & $14.4-16.7$ & RM5657-RM6235 & 2.9 & 0.5 & -0.1 & 4.5 & & \\
\hline \multirow[t]{5}{*}{ BKH } & 3 & $0.5-5.5$ & RM4108-RM5442 & 13.9 & -3.8 & -0.5 & 46.2 & & Ehd4, DTH3 \\
\hline & 5 & $22.3-27.9$ & RM3295-RM5784 & 7.1 & -1.3 & -0.2 & 13.3 & & \\
\hline & 6 & $0.2-5.2$ & RM6467-RM5754 & 18.3 & -2.5 & 0.1 & 59.6 & RFT1, Hd3a & $\mathrm{Hd} 17$ \\
\hline & 7 & $13.4-18.4$ & RM7273-RM6394 & 16.9 & -2.2 & 0.3 & 60.8 & Ghd7 & \\
\hline & 8 & $10.3-14.7$ & RM3395-RM22896 & 9.4 & 3.4 & 0.6 & 36.6 & DTH8 & \\
\hline \multirow[t]{4}{*}{ KNJ } & 5 & $23.9-27.9$ & RM3476-RM5784 & 5.7 & -1.8 & -0.2 & 25.7 & & \\
\hline & 6 & $16.1-29.8$ & RM3615-RM20045 & 15.5 & -4.6 & 1.1 & 31.3 & & \\
\hline & 7 & $26.8-29.4$ & RM1364-RM22164 & 18.3 & -2.0 & 0.5 & 63.3 & & OsPRR37 \\
\hline & 9 & $3.4-9.2$ & RM23736-RM1328 & 2.7 & -1.0 & 0.3 & 4.4 & & \\
\hline \multirow[t]{3}{*}{ BLE } & 3 & 0.5 & RM4108 & 20.1 & -2.8 & -0.5 & 65.9 & & Ehd4, DTH3 \\
\hline & 3 & $30.4-35.6$ & RM3199-RM3329 & 32.1 & -5.2 & 3.4 & 81.2 & Hd6 & Hd16 \\
\hline & 6 & $26.0-28.5$ & RM6395-RM1370 & 3.4 & -1.4 & -0.3 & 6.9 & & \\
\hline
\end{tabular}

${ }^{\mathrm{a}}$ Log-likelihood value. LOD threshold to detect QTLs was determined in each $\mathrm{BC}_{4} \mathrm{~F}_{3}$ population.

${ }^{\mathrm{b}}$ Additive effect of KSH allele on days to heading.

cDominance effect of KSH allele on days to heading.
dPercentage of phenotypic variance explained by QTL.

dPercentage of phenotypic variance explained by QTL.
ePreviously identified heading date genes corresponding to the QTLs detected in this study based on their physical positions on IRGSP 1.0 .

${ }^{f}$ Previously identified heading date genes located near the QTLs detected in this study based on their physical positions on IRGSP 1.0.

The $\mathrm{BC}_{4} \mathrm{~F}_{3}$ populations were derived from crosses between Koshihikari (KSH) and 11 diverse accessions of Asian rice. Abbreviations of rice accessions are described in Table 1. 


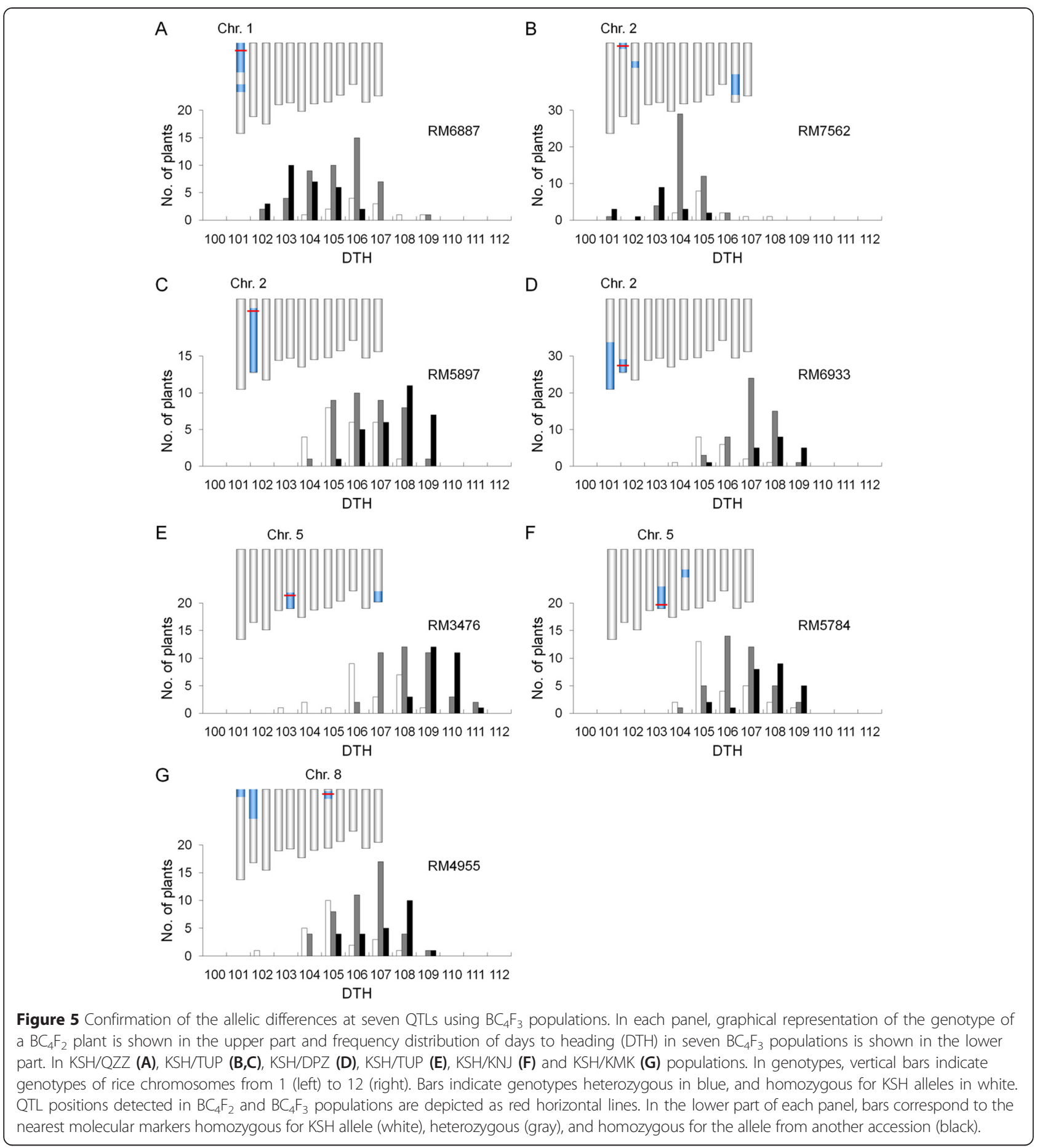

previously isolated genes. Previous study [48] detected heading date QTLs in the $\mathrm{F}_{2}$ populations (4 QTLs) and advanced-backcross populations (12 QTLs) derived from crosses between $\mathrm{KSH}$ and the indica accession Nona Bokra. The QTLs detected in the advancedbackcross populations showed smaller additive effects than the QTLs detected in the $F_{2}$ populations. Therefore, the results of the previous and current studies clearly indicate that advanced-backcross populations are more efficient for detection of small-effect QTLs than the $F_{2}$ populations.

Small-effect QTLs often show inconsistent additive effects across different genetic backgrounds and environmental conditions. However, in this study, a number of small effect QTLs were consistently detected both in the $\mathrm{BC}_{4} \mathrm{~F}_{2}$ and $\mathrm{BC}_{4} \mathrm{~F}_{3}$ populations. In the $366 \mathrm{BC}_{4} \mathrm{~F}_{2}$ 
chr. 1

QZ7
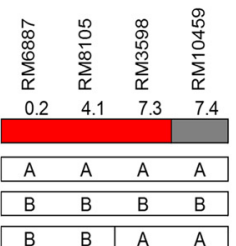

$\operatorname{chr} .2$

TUP

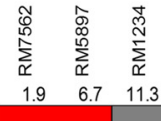

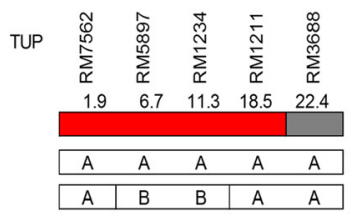

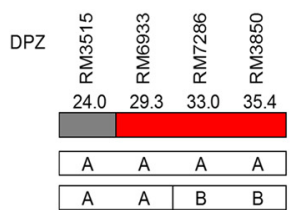

$105.4 \pm 1.1 \quad n=14$

$103.0 \pm 1.2 n=18$

$105.5 \pm 1.3 \quad n=18$

$107.8 \pm 1.0 \quad n=13$

$$
\begin{array}{cl}
\text { DTH } & \text { No. of pla } \\
106.5 \pm 0.6 & n=10 \\
104.3 \pm 1.2 & n=4 \\
104.5 \pm 0.7 & n=2
\end{array}
$$

$$
103.0 \pm 1.2 \quad n=18
$$

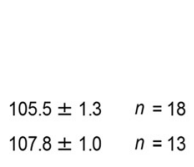

$105.7 \pm 1.0 \quad n=18$

$107.8 \pm 1.1 \quad n=16$ chr. 5

TUP

$\begin{array}{llll}\infty & 0 & \mathbb{N} & \infty \\ \infty & \infty & \mathbb{N} \\ \sum_{\mathbb{N}}^{\infty} & \sum_{\mathbb{N}}^{\infty} & \sum_{\mathbb{N}}^{\infty} & \sum_{\mathbb{N}}^{\infty}\end{array}$
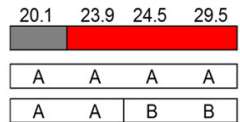

DTH No. of plants

$106.5 \pm 1.3 \quad n=20$

$109.4 \pm 0.8 \quad n=24$

KNJ

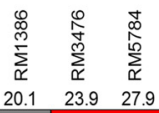

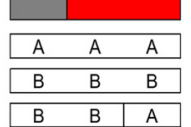

$105.9 \pm 1.4 \quad n=10$

$108.1 \pm 0.6 \quad n=9$

$106.0 \pm 1.4 \quad n=2$

chr. 8

KMK

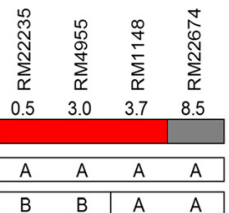

$107.2 \pm 1.2 \quad n=20$

$104.7 \pm 0.9 \quad n=17$

Figure 6 Fine mapping of seven QTLs for days to heading $(D T H)$ under natural day-length conditions in $B_{4} F_{3}$ populations. $B_{4} F_{3}$ progenies were derived from crosses between Koshihikari (KSH alleles[marked with A]) and other accessions of Asian rice (QZZ, TUP, DPZ, and KNJ alleles [marked with B]). Values are means \pm standard deviation. Abbreviations of rice accessions are defined in Table 1. Positions of molecular markers are indicated according to IRGSP 1.0 of the rice genome sequence [52,53]. Red bars indicate marker intervals delimited for each QTL position.

populations, QTLs with LOD >2.0 (255 QTLs), including those with LOD >3.0 (173 QTLs) and >4.0 (134 QTLs) were detected. Among the 255 QTLs, we selected 56 QTLs and confirmed their presence in the $\mathrm{BC}_{4} \mathrm{~F}_{3}$ populations. These results also indicate that advanced-backcross populations are suitable for detection of small-effect QTLs even in small-sized $\mathrm{BC}_{4} \mathrm{~F}_{2}$ populations used in this study.

The advanced-backcross populations are also suitable to delimit the positions of individual small-effect QTLs. For example, in the TUP/KSH populations, two QTLs with opposite genetic effects were detected in a very narrow region on the short arm of chromosome 2. However, these QTLs are independent of each other because of the opposite additive effects of KSH alleles. One QTL was localized closer to the distal end of the short arm of chromosome 2 than the other QTL, which was located within the marker interval from RM7562 to RM1211. In $\mathrm{KMK} / \mathrm{KSH}$ populations, one QTL was detected in the region from the distal end to RM1148 (3.7 Mbp) on the short arm of chromosome 8 . This QTL was located close to DTH8 gene. However, DTH8 gene is located at 4.3 $\mathrm{Mbp}$ from the distal end of the short arm of chromosome 8 , and KMK and KSH share the same allele of DTH8 gene (Additional file 6: Figure S4). Therefore, this
QTL and DTH8 gene are clearly distinct from each other. These examples clearly demonstrate that substitution mapping using advanced-backcross populations is effective for dissecting two independent QTLs located closely to each other.

Previous QTL studies of heading date have identified several small-effect QTLs ( $H d 4, H d 7, H d 8, H d 9, H d 10$, Hd12, Hd13, and Hd17 [27,49-51]). These small-effect QTLs remain poorly characterized and further genetic analyses such as gene cloning and functional characterization are necessary to understand the whole genetic architecture controlling heading date in rice. However, map-based cloning of small-effect QTLs is sometimes difficult because of small phenotypic differences between the QTL alleles. Reverse genetic approaches can be applied to solve this problem. Recently, using next-generation sequencing technology, whole genomic sequences of many accessions have been obtained. Sequence comparison of a particular QTL region among rice accessions is a practical way to nominate probable candidate genes with functional polymorphisms, such as single amino acid substitutions and in-frame deletions or insertions. We can also nominate target genes of interest according to estimation of the gene function based on 
gene annotation information from Rice Annotation Project Database (http://rapdb.dna.affrc.go.jp/ [52,53]) and comprehensive gene expression profiles of microarray analysis from Rice Expression Profile database (http://ricexpro.dna.affrc.go.jp/ [54]). Once a candidate gene is nominated, we should develop transgenic plants including over-expression lines and RNAi lines can be developed. We can also find lines with disrupted target genes in large sets of mutants with insertions of Tos 17 [55] and T-DNA [56-58]. Recently developed TILLING technique allows direct identification of mutation sites within a specific gene [59-61]. The TILLING technique could provide a powerful strategy to obtain lines with target genes disrupted in mutants generated by irradiation or chemical treatment. The approaches described above can be applied to identify genes for heading date QTLs with quite small effects, such as those detected in this study. To date, in addition to 13 genes isolated by map-based cloning strategies, 60 genes have been identified as flowering-time-related genes by genetic analysis of rice mutants and transgenic lines (OGRO database [24]). In this study, some small-effect QTLs were located near the genes reported in previous studies. Spontaneous mutations in these genes might cause functional polymorphisms of these QTLs. Sequencing analyses of these genes and adjacent regions may reveal the genes responsible for heading date differences among Asian rice accessions.

In this study, the chromosomal positions of several large-effect QTLs corresponded to the positions of $H d 6$, Hd3a/RFT1, Hd1, Ghd7, OsPRR37, and DTH8. Sequence polymorphisms in the isolated genes have been detected in the 12 accessions used in this study ( $H d 1$ and $H d 3 a$ [33]; Hd6 [43]; Ghd7 [21]; RFT1 [15]; DTH8 [Additional file 6: Figure S4]) (Additional file 7: Table S3). Sequence polymorphisms in the isolated genes were consistent with locations of the QTLs in this study. For example, in the $\mathrm{HAY} / \mathrm{KSH}$ and QZZ/KSH populations, QTLs were found in the same genomic regions as $H d 1$, Ghd7, OsPRR37, and DTH8. HAY and QZZ had alleles of these genes different from that of $\mathrm{KSH}$. In comparison with $\mathrm{KSH}, \mathrm{HAY}$ had a strong functional allele of $H d 1$, whereas QZZ had a non-functional allele of $H d 1$. HAY and QZZ have non-functional alleles of Ghd7, OsPRR37, and DTH8. The japonica cultivars harboring non-functional alleles of both Ghd7 and OsPRR37 flower extremely early under ND conditions, and are adapted to the northernmost regions (up to $53^{\circ} \mathrm{N}$ latitude) of rice cultivation areas in China, Korea, and Japan [34,62]. We also investigated functional nucleotide polymorphisms in Ehd1, $H d 17$, Hd16, DTH2, Ehd3, and Ehd4 (Additional file 7: Table S3). In the $\mathrm{HAY} / \mathrm{KSH}$ and $\mathrm{QZZ/KSH}$ populations, additional QTLs were detected in the Hd6/Hd16, Ehd4/DTH3, and Hd17/RFT1/Hd3a regions. Because HAY and KSH have the same allele of $H d 6$ and different alleles of $H d 16$, the QTL near Hd6 and Hd16 would be due to difference between HAY (functional Hd16 allele) and KSH (non-functional Hd16 allele). QZZ and KSH have different alleles of Hd6 and Hd16, but the same alleles of Ehd4, DTH3, Hd17, RFT1 and Hd3a. Therefore, the QTLs near Hd6 and $H d 16$ would be due to allelic differences in these genes, but the QTLs near Ehd4, DTH3, Hd17, RFT1, and $H d 3 a$ are probably due to unidentified genes. These results suggest that heading date variations in rice accessions are due to combinations of different alleles of previously isolated and unidentified heading date genes.

Based on the results in this study, we estimated the relationship between the degree of photoperiod sensitivity and the gene pathway regulating heading date in representative accessions (Figure 7). As QZZ is photoperiod-insensitive due to non-functional alleles of $H d 1$, Ghd7, and $D T H 8$, $H d 3 \mathrm{a}$ and RFT1 are transcriptionally up-regulated even under LD conditions. TUP shows weak photoperiod sensitivity due to a non-functional allele of $H d 1$, but the functional allele of DTH8 would transcriptionally down-regulate Ehd1 and RFT1; as a result, TUP shows a later heading date than QZZ under LD conditions. BKH shows weak photoperiod sensitivity mainly due to non-functional alleles of DTH8 and RFT1. The latter fails to induce heading under LD conditions; as a result, BKH shows a later heading date than QZZ. KNJ has functional alleles of almost all heading date genes and therefore shows strong photoperiod sensitivity. In BLE, extremely late heading date ( $>280$ days) under LD conditions was due to a non-functional allele of RFT1. Thus, different allele combinations of the heading date genes in rice accessions can explain the degree of photoperiod sensitivity and heading date variation under various daylength conditions.

Our results suggest that the genetic architecture of heading date in rice is a combination of large-effect QTLs and small-effect QTLs. The sum of additive effects of each QTL reliably estimated the heading date of individual donor accessions $\left(R^{2}=0.78\right)$, although the prediction deviated from the actual heading date in several accessions. Previous studies have reported a complex regulation system that includes epistatic interactions among genes and QTLs for heading date of rice $[2,5,8]$. Consideration of epistatic interactions could more accurately predict heading date of each rice accession on the basis of allelic combinations among a number of genes and QTLs. The complete genetic architecture of heading date would enable precise understanding of differences in heading dates of rice accessions and help to develop new rice accessions.

Genome-wide genetic studies have revealed the divergence of the genetic architecture of flowering time or heading date control in Arabidopsis, maize, sorghum and barley [35,36,63,64]. In Arabidopsis, the genetic 


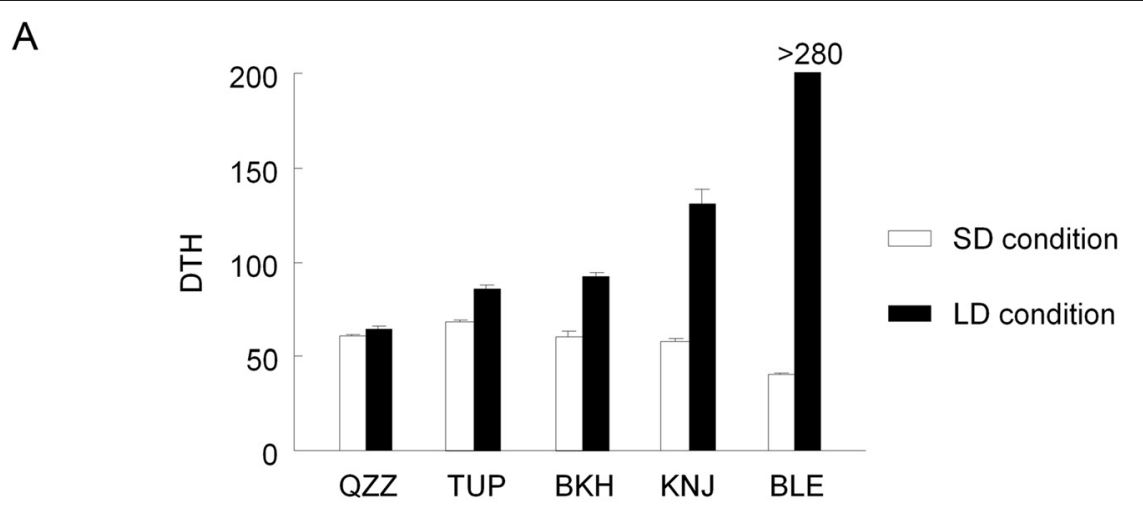

B
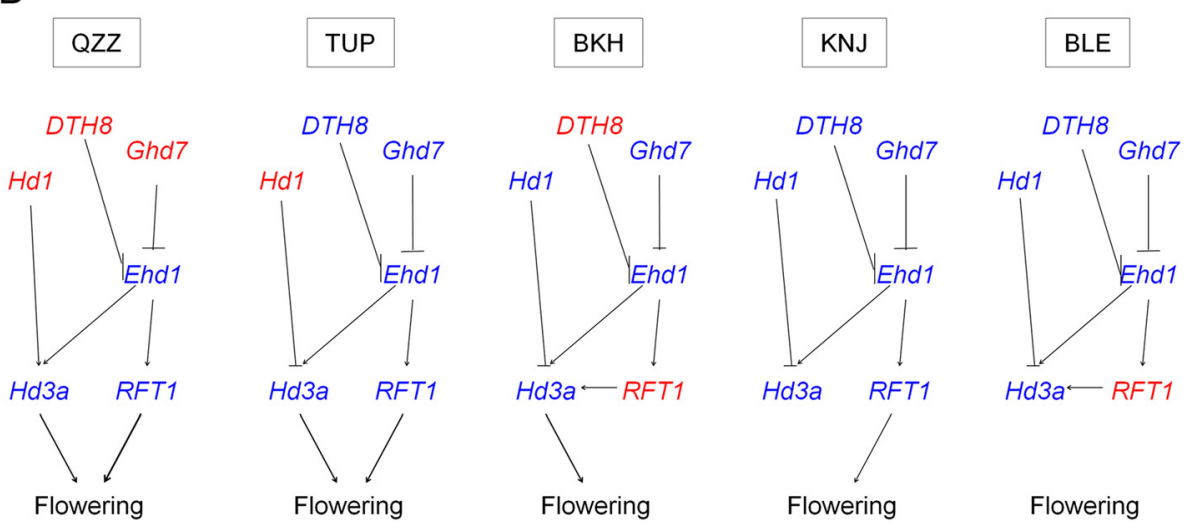

Figure $7 \mathrm{~A}$ model of genetic control of responses to day length in different Asian rice. Six genes were included in the model for five representative Asian rice accessions. Abbreviations of rice accessions are defined in Table 1. (A) Days to heading (DTH) were scored under short-day length (SD) and long-day length (LD) conditions. SD conditions were $10 \mathrm{~h}$ light/14 h dark; LD conditions were $14.5 \mathrm{~h} \mathrm{light/9.5} \mathrm{h} \mathrm{dark.} \mathrm{Values} \mathrm{are} \mathrm{means} \pm$ standard deviation $(n=10)$. (B) Genetic regulatory pathways under LD conditions. Functional alleles are shown in blue and non-functional alleles are shown in red.

basis of flowering time variation is shaped by a small number of genes with large effects such as transcription factor genes FRIGIDA (FRI) and FLOWERING LOCUS $C(F L C)$ that act in the vernalization-responsive pathway [36]. The authors found that most heading date QTLs cluster in as few as five genomic regions, which include $F R I$ and FLC. These results were obtained using $17 \mathrm{~F}_{2}$ populations derived from crosses among 18 distinct accessions representing much of the common genetic diversity of Arabidopsis. In barley, 17 double haploid populations reveal a set of QTLs, such as Photoperiod-H1 (Ppd-H1), Ppd-H2, Vernalization-H1 (Vrn-H1), Vrn-H2 and Early maturity 6, accounted for an important percentage of the heading date variation [64]. It is suggesting that the genetic architectures of heading date are similar between Arabidopsis and barley. In maize, large-scale genetic analysis of $>5,000$ recombinant inbred lines from crosses among 25 diverse inbred lines indicated that heading date is controlled by the additive effect of many QTLs with small effects [35]. In sorghum, 24 populations of recombinant inbred lines of $>1,300$ individuals revealed that a relatively large number of QTLs with small effects control heading date, and 75\% of detected QTLs were localized in the same chromosomal regions as in maize [63]. Largeeffect QTLs have been also reported in sorghum; for example, Ma1 is a major photoperiod sensitivity locus with an additive effect of 40.3 days [65]. Therefore, the genetic architecture of heading date in sorghum is similar to that in rice.

A comparison of the genetic architecture of flowering time or heading date among Arabidopsis, barley, maize, and rice should consider three major points. First, even though the cues involved in genetic control of flowering (Arabidopsis) and heading (rice and barley), such as temperature and day length, are different, the genetic control is similar; a combination of loss- or gain-offunction alleles of major genes is responsible for large variation in flowering time and heading date. Second, difference in the regulatory mechanisms between rice and Arabidopsis (barley) might be due to difference in cultivation areas and reproduction methods of these species. Arabidopsis and barley grow at higher latitudes of the Northern hemisphere than rice and maize, and some Arabidopsis and barley accessions require vernalization 
to avoid flowering during prolonged cold conditions in winter [66,67]. Therefore, allelic differences between vernalization-related genes, such as FRI and FLC in Arabidopsis, and Vrn-H1 and Vrn-H2 in barley, might contribute considerably to natural variation of flowering time and heading date. Third, the genetic architecture is different in rice and maize and regulation by large-effect QTLs has not been detected in maize. Maize was domesticated in tropical areas at low latitudes and cultivation was expanded to higher-latitude areas during selection by humans [68]. Rice domestication was similar to that of maize $[69,70]$. However, maize is an out-crossing species, whereas rice is a self-pollinating species. Therefore, in maize, heading date of individual plants must be substantially synchronous within a local population to ensure mating success [35] and selection in maize breeding may have favored accumulation of many small-effect QTLs to ensure adaptation to different environmental conditions.

\section{Conclusions}

Our results enhance understanding of the genetic architecture of heading date in rice. Comparisons of results between the previous and our studies suggested that genetic architecture in rice were different from those in Arabidopsis, maize, barley and sorghum. In rice, small-effect QTLs largely contributed to a wide range of natural variations of heading date, in addition to large-effect QTLs including 13 genes isolated previously. Both large- and small-effect QTLs could be of great significance in rice breeding for fine-tuning of heading date, which is needed for adaption to certain environmental conditions (i.e., wide ranges of temperature and day-length) and to expand rice growing areas to high-latitude regions.

\section{Additional files}

Additional file 1: Figure S1. Days to heading (DTH) of Koshihikari (KSH) and 11 diverse accessions of Asian rice under short-day length (SD) and long-day length (LD) conditions. Values are means \pm standard deviation $(n=10)$. SD conditions were $10 \mathrm{~h}$ light/14 $\mathrm{h}$ dark; LD conditions were $14.5 \mathrm{~h}$ light/9.5 $\mathrm{h}$ dark. Abbreviations of rice accessions are defined in Table 1.

Additional file 2: Figure S2. Schematic flow chart of development of advanced-backcross populations at $\mathrm{BC}_{4} \mathrm{~F}_{2}$ and $\mathrm{BC}_{4} \mathrm{~F}_{3}$ generations.

Additional file 3: Figure S3. Graphical representations of genotypes of $366 \mathrm{BC}_{4} \mathrm{~F}_{2}$ populations derived from crosses between Koshihikari (KSH) and 11 diverse accessions of Asian rice. Abbreviations of rice accessions are defined in Table 1. Each horizontal bar corresponds to a rice chromosome; chromosomes are arranged from 1 (left) to 12 (right) with each cell indicating one chromosome of a single population. Each horizontal row indicates the genotype of a $\mathrm{BC}_{4} \mathrm{~F}_{2}$ population. Regions heterozygous are shown in black, those homozygous for $\mathrm{KSH}$ alleles are shown in white, and those missing alleles are shown in gray. Graphical genotypes are based on physical distances according to IRGSP 1.0 of the rice genome sequence [52,53].

Additional file 4: Table S1. Frequency distributions for days to heading $(\mathrm{DTH})$ in $366 \mathrm{BC}_{4} \mathrm{~F}_{2}$ populations derived from crosses between Koshihikari $(\mathrm{KSH})$ and 11 diverse accessions of Asian rice. Fill in cells show the number of individual plants: less than five (right pink) and more than six (dark pink). Abbreviations of rice accessions are defined in Table 1.

Additional file 5: Table S2. List of heading date QTLs detected in $\mathrm{BC}_{4} \mathrm{~F}_{2}$ populations derived from crosses between Koshihikari (KSH) and 11 diverse accessions of Asian rice. QTLs written by bold characters indicate those confirmed in $\mathrm{BC}_{4} \mathrm{~F}_{3}$ populations. Abbreviations of rice accessions are defined in Table 1.

Additional file 6Figure S4. Substitution (boxes) and insertion/deletion (-) polymorphisms of amino acids in the DTH8 protein in 12 diverse accessions of Asian rice. Abbreviations of rice accessions are defined in Table 1. The conserved histon-fold motif domain in DTH8 is indicated in orange. Numbers under the DTH8 diagram indicate the positions of polymorphic sites. Numbers on the right side show the total length of each predicted amino acid sequence. The regions with amino acid changes due to a frame shift are labeled with asterisks. Stop indicates a stop codon. Accession numbers of each sequence are DDBJ: LC016712LC016721.

Additional file 7: Table S3. Allele types of 13 heading date genes isolated by previous studies in 12 diverse accessions of Asian rice. Abbreviations of rice accessions are defined in Table 1. Red and blue characters indicate early heading and late heading alleles, respectively. Numbers, nucleotides, and lower-case letters are respective alleles identified in the previous studies: DTH2 [28]: Ehd4 [31]: DTH3 [26]: Hd6 [43]: Hd16 [29]: Hd17 [27]: RFT1 [15]: Hd3a and Hd1 [33]: Ghd7 [21]: OSPRR37 [32]: DTH8 [25]: Ehd1 [18]. Complete genomic sequences of Hd1, Hd6, Ghd7, Hd3a, RFT1 and DTH8 were determined in the 12 diverse accessions. Functional nucleotide polymorphisms of Ehd1, DTH2, DTH3, Ehd4, Hd17, Hd16 and OsPRR37 were genotyped by gene-specific markers in the 12 diverse accessions.

\section{Abbreviations}

QTLs: Quantitative trait loci; DTH: Days to heading; SD: Short-day length; LD: Long-day length; ND: Natural-day length; KSH: Koshihikari; HAY: Hayamasari; QZZ: Qiu Zhao Zong; TUP: Tupa 121-3; MUH: Muha; BAS: Basilanon; DPZ: Deng Pao Zhai; KMK: Khao Mac Kho; NAB: Naba; BKH: Bei Khe; KNJ: Khao Nam Jen; BLE: Bleiyo; OsGl: Rice GIGANTEA; Hd1: Heading date 1; Hd3a: Heading date 3a; Hd6: Heading date 6; RFT1: Rice flowering locus T 1; Ehd1: Early heading date 1; Ghd7: Grain number, plant height and heading date 7; DTH8: Days to heading on chromosome 8; DTH3: Days to heading on chromosome 3; Hd17: Heading date 17; DTH2: Days to heading on chromosome 2; Hd16: Heading date 16; Ehd4: Early heading date 4; OsPRR37: Oryza sativa pseudo-response regulator 37.

\section{Competing interests}

The authors declare that they have no competing interests.

\section{Authors' contributions}

$\mathrm{KH}, \mathrm{YN}$ and MY participated in the design, coordination of the study and wrote the manuscript. KH, YN, NO, TS, KM, EOT, TT and MY performed the field evaluations. TS and KE performed sequencing analysis. $K H, Y N, N O, T S$, KE, KM, EOT, TT, KS, FTS, JY, RM, YU, AF, TU, SY, UY, TT, TI, KK, TH, EY, SA, HN, AS, TS, IK, SI, TM, NK, KN, TA, SF, TY and MY developed the advancedbackcross progenies. All authors read and approved the final manuscript.

\section{Acknowledgements}

We are grateful to all technical staff of the Rice Applied Genomics Research Unit for their technical assistance and management of the rice fields of the Field Management Division of the NIAS. This work was supported by the Ministry of Agriculture, Forestry and Fisheries of Japan (Integrated Research Project for Plant, Insect, and Animal using Genome Technology, QT1005; Genomics for Agricultural Innovation, NVR0001; Research Project for Genomics-based Technology for Agricultural Improvement, IVG2002).

\section{Author details}

${ }^{1}$ National Institute of Agrobiological Sciences, 2-1-2 Kannondai, 305-8602 Tsukuba, Ibaraki, Japan. ${ }^{2}$ Institute of the Society for Techno-innovation of Agriculture, Forestry and Fisheries, 446-1 Ippaizuka, Kamiyokoba, 305-0854 Tsukuba, Ibaraki, Japan. 
Received: 3 February 2015 Accepted: 22 April 2015

Published online: 08 May 2015

\section{References}

1. Thomas B, Vince-Pure D. Photoperiodium in plants. 2nd ed. San Diego, California: Academic; 1997.

2. Bentley A, Jensen E, Mackay I, Honicka H, Fladung M, Hori K, et al. Flowering time: genomics and breeding for climate-resilient crops, vol. 2. Berlin: Springer; 2013.

3. Izawa T: Daylength measurements by rice plants in photoperiodic short-day flowering. In: International Review of Cytology. Edited by Kwang WJ, vol. Volume 256. London: Academic Press; 2007: 191-222.

4. Greenup A, Peacock WJ, Dennis ES, Trevaskis B. The molecular biology of seasonal flowering-responses in Arabidopsis and the cereals. Ann Bot. 2009:103(8):1165-72.

5. Tsuji H, Taoka K-i, Shimamoto K. Regulation of flowering in rice: two florigen genes, a complex gene network, and natural variation. Curr Opin Plant Biol. 2011;14(1):45-52

6. Brambilla V, Fornara F. Molecular control of flowering in response to day length in rice. J Integr Plant Biol. 2013;55(5):410-8.

7. Tsuji H, Taoka K-i, Shimamoto K. Florigen in rice: complex gene network for florigen transcription, florigen activation complex, and multiple functions. Curr Opin Plant Biol. 2013;16(2):228-35.

8. Matsubara K, Hori K, Ogiso-Tanaka E, Yano M. Cloning of quantitative trait genes from rice reveals conservation and divergence of photoperiod flowering pathways in Arabidopsis and rice. Front Plant Sci. 2014;5:193.

9. Shrestha R, Gomez-Ariza J, Brambilla V, Fornara F. Molecular control of seasonal flowering in rice, arabidopsis and temperate cereals. Ann Bot. 2014;114(7):1445-58.

10. Yano M, Katayose Y, Ashikari M, Yamanouchi U, Monna L, Fuse T, et al. HdT, a major photoperiod sensitivity quantitative trait locus in rice, is closely related to the Arabidopsis flowering time gene CONSTANS. Plant Cell. 2000;12(12):2473-84.

11. Kojima S, Takahashi Y, Kobayashi Y, Monna L, Sasaki T, Araki T, et al. Hd3a, a rice ortholog of the Arabidopsis FT gene, promotes transition to flowering downstream of $\mathrm{Hd} 1$ under short-day conditions. Plant Cell Physiol. 2002;43(10):1096-105.

12. Takahashi Y, Shomura A, Sasaki T, Yano M. Hd6, a rice quantitative trait locus involved in photoperiod sensitivity, encodes the a subunit of protein kinase CK2. Proc Natl Acad Sci U S A. 2001;98(14):7922-7.

13. Ogiso E, Takahashi Y, Sasaki T, Yano M, Izawa T. The role of casein kinase II in flowering time regulation has diversified during evolution. Plant Physiol. 2010;152(2):808-20.

14. Tamaki S, Matsuo S, Wong HL, Yokoi S, Shimamoto K. Hd3a protein is a mobile flowering signal in rice. Science. 2007;316(5827):1033-6.

15. Ogiso-Tanaka E, Matsubara K, Yamamoto S-i, Nonoue Y, Wu J, Fujisawa $\mathrm{H}$, et al. Natural variation of the RICE FLOWERING LOCUS T 1 contributes to flowering time divergence in rice. PLoS One. 2013;8(10):e75959.

16. Komiya R, Ikegami A, Tamaki S, Yokoi S, Shimamoto K. Hd3a and RFT1 are essential for flowering in rice. Development. 2008;135(4):767-74.

17. Komiya R, Yokoi S, Shimamoto K. A gene network for long-day flowering activates RFT1 encoding a mobile flowering signal in rice. Development. 2009;136(20):3443-50.

18. Doi K, Izawa T, Fuse T, Yamanouchi U, Kubo T, Shimatani Z, et al. Ehd1, a B-type response regulator in rice, confers short-day promotion of flowering and controls FT-like gene expression independently of Hd1. Gene Dev. 2004;18(8):926-36.

19. Xue $W$, Xing $Y$, Weng $X$, Zhao $Y$, Tang $W$, Wang $L$, et al. Natural variation in $G$ Gd 7 is an important regulator of heading date and yield potential in rice. Nat Genet. 2008:40(6):761-7.

20. Itoh H, Izawa T. The coincidence of critical day length recognition for florigen gene expression and floral transition under long-day conditions in rice. Mol Plant. 2013;6(3):635-49.

21. Ebana K, Shibaya T, Wu J, Matsubara K, Kanamori H, Yamane H, et al. Uncovering of major genetic factors generating naturally occurring variation in heading date among Asian rice cultivars. Theor Appl Genet. 2011;122(6):1199-210.

22. Yonemaru J-i, Yamamoto T, Fukuoka S, Uga Y, Hori K, Yano M. Q-TARO: QTL annotation rice online database. Rice. 2010;3(2-3):194-203.
23. Youens-Clark K, Buckler E, Casstevens T, Chen C, DeClerck G, Derwent P, et al. Gramene database in 2010: updates and extensions. Nucleic Acids Res. 2011;39 suppl 1:D1085-94.

24. Yamamoto E, Yano M, Yamamoto T, Yonemaru J-i. OGRO: The oerview of functionally characterized genes in rice online database. Rice. 2012;5(1):26.

25. Wei X, Xu J, Guo H, Jiang L, Chen S, Yu C, et al. DTH8 suppresses flowering in rice, influencing plant height and yield potential simultaneously. Plant Phisiol. 2010;153(4):1747-58.

26. Bian XF, Liu X, Zhao ZG, Jiang L, Gao H, Zhang YH, et al. Heading date gene, dth3 controlled late flowering in $\mathrm{O}$. Glaberrima Steud. by down-regulating Ehd1. Plant Cell Rep. 2011;30(12):2243-54.

27. Matsubara K, Ogiso-Tanaka E, Hori K, Ebana K, Ando T, Yano M. Natural variation in Hd17, a homolog of Arabidopsis ELF3 that is involved in rice photoperiodic flowering. Plant Cell Physiol. 2012;53(4):709-16.

28. Wu W, Zheng X-M, Lu G, Zhong Z, Gao H, Chen L, et al. Association of functional nucleotide polymorphisms at DTH2 with the northward expansion of rice cultivation in Asia. Proc Natl Acad Sci U S A. 2013;110(8):2775-80.

29. Hori K, Ogiso-Tanaka E, Matsubara K, Yamanouchi U, Ebana K, Yano M. Hd16, a gene for casein kinase $\mathrm{I}$, is involved in the control of rice flowering time by modulating the day-length response. Plant J. 2013;76(1):36-46.

30. Kwon C-T, Yoo S-C, Koo B-H, Cho S-H, Park J-W, Zhang Z, et al. Natural variation in Early floweringl contributes to early flowering in japonica rice under long days. Plant Cell Environ. 2014;37(1):101-12.

31. Gao H, Zheng X-M, Fei G, Chen J, Jin M, Ren Y, et al. Ehd4 encodes a novel and Oryza-genus-specific regulator of photoperiodic flowering in rice. PLoS Genet. 2013;9(2), e1003281

32. Koo B-H, Yoo S-C, Park J-W, Kwon C-T, Lee B-D, An G, et al. Natural variation in OsPRR37 regulates heading date and contributes to rice cultivation at a wide range of latitudes. Mol Plant. 2014;6(6):1877-88.

33. Takahashi Y, Teshima KM, Yokoi S, Innan H, Shimamoto K. Variations in Hd1 proteins, Hd3a promoters, and Ehd1 expression levels contribute to diversity of flowering time in cultivated rice. Proc Natl Acad Sci U S A. 2009;106(11):4555-60.

34. Fujino K, Yamanouchi U, Yano M. Roles of the Hd5 gene controlling heading date for adaptation to the northern limits of rice cultivation. Theor Appl Genet. 2013;126(3):611-8.

35. Buckler ES, Holland JB, Bradbury PJ, Acharya CB, Brown PJ, Browne C, et al. The genetic architecture of maize flowering time. Science. 2009;325(5941):714-8.

36. Salomé PA, Bomblies K, Laitinen RAE, Yant L, Mott R, Weigel D. Genetic architecture of flowering-time variation in Arabidopsis thaliana. Genetics. 2011;188(2):421-33.

37. Beavis WD. QTL analyses: power, precision, and accuracy. New York: CRC Press; 1998.

38. Kojima Y, Ebana K, Fukuoka S, Nagamine T, Kawase M. Development of an RFLP-based rice diversity research set of germplasm. Breed Sci. 2005:55(4):431-40

39. Fukuoka S, Nonoue Y, Yano M. Germplasm enhancement by developing advanced plant materials from diverse rice accessions. Breed Sci. 2010;60(5):509-17.

40. Shibaya T, Nonoue Y, Ono N, Yamanouchi U, Hori K, Yano M. Genetic interactions involved in the inhibition of heading by heading date QTL, Hd2 in rice under long-day conditions. Theor Appl Genet. 2011;123(7):1133-43.

41. McCouch SR, Teytelman L, Xu Y, Lobos KB, Clare K, Walton M, et al. Development and mapping of 2240 new SSR markers for rice (Oryza sativa L.). DNA Res. 2002;9(6):257-79.

42. International Rice Genome Sequencing Project. The map-based sequence of the rice genome. Nature. 2005;436:793-800.

43. Yamane $H$, Ito $T$, Ishikubo $H$, Fujisawa M, Yamagata H, Kamiya $K$, et al. Molecular and evolutionary analysis of the Hd6 photoperiod sensitivity gene within genus Oryza. Rice. 2009;2(1):56-66.

44. Lander E, Green P, Abrahamson J, Barlow A, Daly M, Lincoln S, et al. Mapmaker: an interactive computer package for constructing primary genetic linkage maps of experimental and natural populations. Genomics. 1987;:1:174-81

45. Kosambi DD. The estimation of map distance from recombination values. Ann Eugen. 1944;12:172-5.

46. Basten C, Weir B, Zeng Z. QTL cartographer, ver. 1.17. Raleigh, NC: Department of Statistics, North Carolina State University; 2005.

47. Sanger F, Nicklen S, Coulson AR. DNA sequencing with chain-terminating inhibitors. Proc Natl Acad Sci U S A. 1977;74(12):5463-7. 
48. Uga Y, Nonoue $Y$, Liang ZW, Lin HX, Yamamoto S, Yamanouchi U, et al. Accumulation of additive effects generates a strong photoperiod sensitivity in the extremely late-heading rice cultivar 'Nona Bokra'. Theor Appl Genet. 2007;114(8):1457-66.

49. Lin SY, Sasaki T, Yano M. Mapping quantitative trait loci controlling seed dormancy and heading date in rice, Oryza sativa L., using backcross inbred lines. Theor Appl Genet. 1998;96(8):997-1003.

50. Lin H, Ashikari M, Yamanouchi U, Sasaki T, Yano M. Identification and characterization of a quantitative trait locus, $\mathrm{Hd}$, controlling heading date in rice. Breed Sci. 2002;52:35-41.

51. Lin H, Liang Z-W, Sasaki T, Yano M. Fine mapping and characterization of quantitative trait loci $\mathrm{Hd} 4$ and $\mathrm{Hd} 5$ controlling heading date in rice. Breed Sci. 2003:53(1):51-9.

52. Kawahara Y, de la Bastide M, Hamilton J, Kanamori H, McCombie WR, Ouyang $\mathrm{S}$, et al. Improvement of the Oryza sativa Nipponbare reference genome using next generation sequence and optical map data. Rice. 2013;6(1):4.

53. Sakai H, Lee SS, Tanaka T, Numa H, Kim J, Kawahara Y, et al. Rice annotation project database (RAP-DB): an integrative and interactive database for rice genomics. Plant Cell Physiol. 2013;54(2):e6.

54. Sato $Y$, Takehisa H, Kamatsuki K, Minami H, Namiki N, Ikawa H, et al. RiceXPro Version 3.0: expanding the informatics resource for rice transcriptome. Nucleic Acids Res. 2013;41(D1):D1206-13.

55. Hirochika $\mathrm{H}$. Insertional mutagenesis with Tos 17 for functional analysis of rice genes. Breed Sci. 2010;60(5):486-92.

56. An G, Lee S, Kim S-H, Kim S-R. Molecular genetics using T-DNA in rice. Plant Cell Physiol. 2005;46(1):14-22.

57. Guiderdoni E, An G, Yu S-M, Hsing Y-i, Wu C. T-DNA insertion mutants as a resource for rice functional genomics. In: Rice Functional Genomics. New York: Springer; 2007. p. 181-221.

58. Kim SL, Choi M, Jung K-H, An G. Analysis of the early-flowering mechanisms and generation of T-DNA tagging lines in Kitaake, a model rice cultivar. J Exp Bot. 2013;64:4169-82.

59. Till B, Cooper J, Tai T, Colowit P, Greene E, Henikoff S, et al. Discovery of chemically induced mutations in rice by TILLING. BMC Plant Biol. 2007;7(1):19.

60. Tsai H, Howell T, Nitcher R, Missirian V, Watson B, Ngo KJ, et al. Discovery of rare mutations in populations: TILLING by sequencing. Plant Physiol. 2011;156(3):1257-68.

61. Cooper J, Henikoff S, Comai L, Till B: TILLING and ecotilling for rice. In: Rice Protocols. Edited by Yang Y, vol. 956. New York: Humana Press; 2013: 39-56.

62. Nonoue Y, Fujino K, Hirayama Y, Yamanouchi U, Lin SY, Yano M. Detection of quantitative trait loci controlling extremely early heading in rice. Theor Appl Genet. 2008;116(5):715-22.

63. Mace ES, Hunt $\mathrm{CH}$, Jordan DR. Supermodels: sorghum and maize provide mutual insight into the genetics of flowering time. Theor Appl Genet. 2013;126(5):1377-95.

64. Cuesta-Marcos A, Casas AM, Yahiaoui S, Gracia MP, Lasa JM, Igartua E. Joint analysis for heading date QTL in small interconnected barley populations. Mol Breeding. 2008:21:383-99.

65. Murphy RL, Klein RR, Morishige DT, Brady JA, Rooney WL, Miller FR, et al. Coincident light and clock regulation of pseudoresponse regulator protein 37 (PRR37) controls photoperiodic flowering in sorghum. Proc Natl Acad Sci U S A. 2011;108(39):16469-74.

66. Caicedo AL, Stinchcombe JR, Olsen KM, Schmitt J, Purugganan MD. Epistatic interaction between Arabidopsis FRI and FLC flowering time genes generates a latitudinal cline in a life history trait. Proc Natl Acad Sci U S A. 2004;101(44):15670-5.

67. Rosloski SM, Jali SS, Balasubramanian S, Weigel D, Grbic V. Natural diversity in flowering responses of Arabidopsis thaliana caused by variation in a tandem gene array. Genetics. 2010;186(1):263-76.

68. Hamblin MT, Warburton ML, Buckler ES. Empirical comparison of simple sequence repeats and single nucleotide polymorphisms in assessment of maize diversity and relatedness. PLoS One. 2007;2(12), e1367.

69. Sweeney M, McCouch S. The complex history of the domestication of rice. Ann Bot. 2007;100(5):951-7.

70. Sang T, Ge S. Understanding rice domestication and implications for cultivar improvement. Curr Opin Plant Biol. 2013:16(2):139-46.

\section{Submit your next manuscript to BioMed Central and take full advantage of:}

- Convenient online submission

- Thorough peer review

- No space constraints or color figure charges

- Immediate publication on acceptance

- Inclusion in PubMed, CAS, Scopus and Google Scholar

- Research which is freely available for redistribution

Submit your manuscript at www.biomedcentral.com/submit 